This paper isthe result of deliberations of the Society's discussion group on SEISMIC DESIGN OF DUCTILE MOMENT RESISTING REINFORCED CONCRETE FRAMES

\title{
SECTION K
}

\section{PARTS, PORTIONS AND SECONDARY ELEMENTS}

\section{N. W. Allardice*}

\section{$\mathrm{Kl} .0 \mathrm{SCOPE}$}

KI.I NZS 4203 defines secondary elements in section 1.1 .3 , and in sections $3.4 .9,3.6$, $3.7,3.8$ and 3.9 sets out design seismic induced loads, anticipated deformation and special detailing requirements related to structural performance for parts, portions or particular elements of buildings. In addition to structural design requirements other factors such as fire ratings, smoke stopping, risks of damage and serviceability after an earthquake require consideration early in the design concept. These additional factors will often influence the selection of the type of structure to be adopted. Where a ductile frame is adopted these factors are likely to influence the layout and size of primary structural members in order to avoid or minimise problems of incompatibility between demands for seismic separation to accommodate relative movement, and non structural considerations, such as fire resistance and serviceability.

\section{K2.0 GENERAL OBLIGATIONS}

K2.1 The structural engineer engaged to design a ductile framed structure to comply with NZS 4203 should advise the Principal Advisor or Client of the need for the following:

K2.1.01 Provision of a separation distance between the building and its site boundary or between adjacent buildings or between adjacent wings of the same building or at thermal expansion joints.

K2.1.02 Provision for separation of secondary elements from the main structure.

K2.1.03 Engineering design requirements of parts, portions and secondary elements and their fixings.

\section{K2.1.04 Engineering design of plant fixings.}

K2.1.05 Co-ordination of the structural and fire resistance requirements for secondary elements.

K2.1.06 An assessment of the risks of damage to secondary elements following a seismic disturbance and the implications of such damage on the delay and extent of remedial work which may be needed before the building can be brought back into normal service.

K2.1.07 Engineering design requirements for items such as machinery, shelving, etc., traditionally considered as fittings and furnishings but now subject to specific seismic design loads.

K2.1.08 Risks involved in variations to

* Consulting Engineer, Auckland. structural elements without approval of the structural designer.

\section{K3.0 SEISMIC INDUCED STRUCTURAL DEFLECTIONS}

K3.1 Early in the selection of design concepts an estimate should be made of the approximate order of roof level and interstorey deflection for the framed structure under the code Loadings which should then be increased by the modification factors for the limited requirement of the code for post-elastic behaviour.

K3.2 On the basis of these estimated deflections the need for separation of particular elements should be confirmed and the elements affected listed.

K3.3 The flexibility of the primary structure may impose unacceptable requirements for separation in which case the geometry of the structure or the member sizes should be revised to bring deflections within the limitation which the detailing can accommodate. Re-estimate of deflections may be needed for the revised structural schematic or concept.

K3.4 A final check should be made of the estimated overall and interstorey displacements from the completed structural drawings to ensure that the original assessments are valid for the design as detailed.

\section{K4.0 SEPARATION OF ELEMENTS}

K4.1 Where seismic induced interstorey deflections exceed the limits set down in NZS 4203 Clause 3.8.3, the structural engineer should consult with the principal advisor regarding the elements affected, the clearances required and possible conflicting requirements between separation and fire ratings, fire stopping, smoke stopping and sound attenuation. The feasibility of meeting the conflicting demands for each of these requirements where applicable should be reviewed and resolved or the basic concepts amended.

K4.2 On completion of the construction drawings the structural designer should check the details or performance specifications prepared by architects or services engineers for adequacy of fixings and support of parts and portions and adequacy of provisions made for accommodating relative movements. Any inadequacies or discrepancies identified should be referred back to the party concerned for resolution.

\section{K5.0 SEISMIC INDUCED AND OTHER DESIGN LOADS}

K5.1 The probable seismic induced design loads for each part or portion or secondary element should be calculated in accordance 
with sections 3.4 .9 and 3.6 and Table 9, taking into account the constructional materials. Other requirements for gravity load, wind load and as appropriate, handling and erection forces, should be assessed and appropriate load combinations considered.

K5.2 The seismic induced loads given in NZS 4203 are intended for use in the Strength Method of design as set out in section 1.3.2 of NZS 4203. Where material design codes suitable for using a strength method are not available, or not recognised by approving authorities having jurisdiction over the work, then the alternative strength method set out in section 1.3 .3 should be followed.

K5.3 The adequacy of the structural component of the part, portion or secondary element should be checked for the alternative seismic and wind loading condition which may be required. This can apply to elements which are normally stabilised by members of negligible or low fire rating, but which must be capable of standing unsupported after these stabilising members have failed in a fire as required by clause 5.14 of NZS 1900 Chapter 5, "Fire Resisting Construction and Means of Egress".

K5.4 Deflection of the structural components of parts, portions or secondary elements should be checked under their individual seismic loads and revised as necessary to limit deflections in accordance with the appropriate material design code or standard.

K5.5 The seismic induced design loads for the structural components of a part, portion, or element are not necessarily statically compatible with the seismic design loads for connection or supports of that same part, portion or element. Guidance on this is given in Table 8, Table 9 and the commentary section C. 3.4.9 of NZS 4203. Members restraining or supporting parts, portions or elements should be capable of resisting the seismic induced code loads for that part, portion or element.

K5. 6 The seismic induced forces in primary structural elements which do not participate in the seismic resistance of the structure but which are linked to it, and undergo the same deformations, should be calculated using the deformations given in clause 3.8. Such elements should be designed to resist these forces using the strength Method of section 1.3.2.

\section{K6. 0 NON STRUCTURAL DESIGN FACTORS}

K6.1 The structural designer should either check or draw to the attention of the principal advisor the need to check that the durability and fire rating requirements for fixings and for support and stabilising members to secondary elements have been provided in accordance with the related building by-laws. Also, the method of providing for such requirements should be checked to ensure that it is compatible with provisions for separation and relative movement between primary and secondary elements.

K6.2 The NZS 4203 code requirements for relative displacement between secondary elements and primary structure should be compared with the probable amount that will result under an infrequent severe earthquake.
An assesment should be made of the nature and degree of damage likely to fire and smoke stop partitions and to the feasibility of access for possible subsequent repair.

K6.3 The structural designer should also check that stiff secondary elements such as part height masonry walls bridging seismic and thermal gaps and service ducts have not been introduced in such a manner as to negate design assumptions of structural behaviour and be a cause of possible damage to the primary structural elements.

\section{COMMENTARY}

CKI.0 SCOPE

\section{CKl.I General}

Secondary elements are defined in broad terms in section 1.1 .3 of NZS 4203 In the relevant clauses, tables and commentaries the same items are variously referred to as parts, portions and elements.

In the design of secondary elements supported by a relatively flexible framed structure there are risks of incompatibility between demands for seismic separation to accommodate relative movements and the requirements for fire and smoke stopping, sound attenuation and security. The main categories of secondary elements requiring special early consideration for these possible conflicts are as follows:-

External Walls and Windows

Stairwells

Liftwells

Vertical Service Ducts

Tenancy Partitions

Partitions within a Tenancy

Ceilings

\section{(a) External Walls}

In many cases fire ratings up to 4 hours can be called for on external walls. Where fire ratings are called for there are, by inference, requirements for smoke stopping and limitation of gas flow to prevent combustible materials passing through a wall which is intended to prevent the spread of fire to or from the enclosed spaces for a specific period of time.

Any separation provided for seismic movement on a fire rated wall requires smoke stopping and fire rating and this can be difficult to achieve unless a double skin type construction is adopted. Where no provision, or inadequate provision, is made for seismic movements interaction between the walls and primary structural elements could result in modification of the assumed structural behaviour, collapse of walls or loss of weather resistance.

It should not be overlooked that interaction between walls and primary elements also occurs where walls are constructed as part or full height vertical cantilevers separated at ends and top and that such interaction may significantly alter the stiffness of frames.

(b) Stairwells, Liftwells and Service Ducts

The secondary elements forming the 
enclosure to such items require fire rating and by inference also require smoke and inflammable gas stopping.

Materials commonly used for these enclosures are fire rated timber partitions and, to a lesser degree, masonry partitions. Where such partitions are supported at each floor level in a flexible framed structure there can be difficulties in achieving and maintaining the required level of fire protection.

One appropriate solution would be to construct these partitions as self supporting structures extending up from foundation level and anchored laterally at selected floor levels so that they may deform and follow the movements in the primary structure. Deformation of the main structure would need to be limited to within the levels of strain which the constructional material of the wall can accommodate at the curvature induced by the geometry of the well walls in following the primary structure.

Well walls mutually self supporting at each floor level can readily accommodate movement; but there are problems of fire and smoke stopping at the head and there can be interaction problems at junctions with ceilings supported from the slab above.

Well walls supported at each floor level can accommodate movements by tilting under displacements normal to their plane and by relative sliding at the head for movements along their plane. Problems arise at intersecting walls which must result in damage and the loss of fire protection until repairs are effected. Achieving effective fire rating at sliding head joints can also be difficult.

Provisions need to be made for access for repair to restore the fire protection requirements of such partitions.

Details employed overseas need to be carefully scrutinised for applicability under New Zealand conditions. For instance Japanese structures are often designed for higher code loadings than those in New Zealand and/or incorporate energy dissipating walls or braces. Such buildings are subject to small deformations in severe earthquakes and the demands on separation distances and joint design may differ significantly from those required in New Zealand. Details of the tests carried out and the test requirements are also not adequately known. There is an urgent need for testing of details constructed of local materials designed to meet New Zealand code requirements. All details proposed by the designer should therefore be checked with the Fire protection Authority for acceptability before adoption.

\section{(c) Tenancy Partitions}

Depending on the nature of the occupancy these are required to have fire ratings ranging between one and four hours and by inference require smoke and gas stopping.

Where these do not extend through. several floors in the building, as is often the case, the relative merits of self supporting and propped partitions need consideration. As described above, a degree of damage is inevitable at moving joints or at junctions of intersecting partitions.

\section{(d) Subdivision within a Tenancy}

Except in special circumstances, subdivision inside a tenancy does not usually involve requirements for fire ratings. Often the problem is to provide sound attenuation and limit the extent of seismic damage and subsequent repair. Achieving this will inevitably result in the partitions inducing some resistance to seismic movements and again expendable joints at intersections of partitions are almost inevitable.

\section{(e) Ceilings}

Current attempts at designing ceilings to comply with NZS 4203 are based on bracing the ceiling back to the soffit of the supporting slab above. This simplifies problems of relative movement between the slab, above ceiling services and the ceiling itself. As mentioned in (b) above, such an approach requires consideration of possible seismic induced relative movements or reactions at the junction of ceilings with partitions or with walls to ducts and wells.

\section{CK2.1 General Obligations}

The requirements of NZS 4203 place new responsibilities on the structural engineer for aspects of design of elements which traditionally have been considered the responsibility of others. His interest in such matters is sometimes unwelcome because of design restrictions and cost implications. To avoid possible charges of negligence he should at least aquaint the Principal Advisor of these factors.

CK2.1.04 It will often be necessary for the structural engineer to provide seismic design loadings for plant fixings. Also in cases where there is no building services engineer employed or where he is not experienced in the design of earthquake resistant plant fixings, then the entire design work for such fixings will need to be done by the structural engineer.

\section{CK 4.0 SEPARATION OF ELEMENTS}

There is a risk that the requirements for separation will be overlooked or rendered partially or totally ineffective in the detailing. It would be prudent to check that the original design intentions have been carried into the detailing. Carrying out such a check is often difficult to achieve in practice and can be time consuming without being fully effective.

\section{CK5.0 SEISMIC INDUCED AND OTHER DESIGN LOADS}

The construction materials described below are those normally used for secondary elements in ductile concrete framed structures.

\section{(a) Window Sections}

Windows of steel or aluminium sections anchored at the base and using a channel support to permit sliding and relative movement at the head and jambs is now a well accepted method of accommodating 
seismic movements and is readily understood by the major manufacturers.

Where metal windows are specified on a performance type specification the structural designer is unlikely to be involved in design and detailing, but he could expect to be required to assist in formulating displacement and loading requirements for the specification.

When the specification is being drafted the structural designer should make it clear that the window suppliers design details and calculations should be submitted for checking and comment before fabrication commences, unless provision is made in the specification for full size load/deflection testing to demonstrate compliance with the specification requirements.

Care needs to be taken to provide for relief or relative movement between the typical tilting window details which result from the propping action of the sliding head channel and any stiff abutting partitions with sliding head details.

\section{(b) Reinforced Masonry Walls}

Such walls may be used either as firerated or non fire-rated walls.

Where no fire rating is required, block walls in any storey can be erected as vertical beams propped against face loads with a sliding head joint. This results in problems at wall intersections. Alternatively, such walls can be designed as self supporting systems extending up from floor slab with a separation gap at the head. However, if there are sound attenuation requirements then inevitably the detailing requirement will result in these walls picking up some loading under seismic movement of the primary structure.

Where a fire rating is required then the demands on separation and stiffness are incompatible particularly if the use of asbestos rope is precluded for health reasons or as being too incompressible, or if other flexible fillers do not meet fire rating requirements.

On external walls the problem can also be partially overcome with cavity construction located with a nib on the primary structure between the two shells of the wall system. On single skin internal walls one possible alternative is to carry these walls as independent structures from foundation level as described in CKl.l (b). Where such an approach is adopted with masonry walls it may be necessary to introduce vertical separation joints to reduce the stiffness of such walls.

Generally the use of reinforced masonry walls should be avoided or approached with extreme caution in ductile framed structures.

\section{(c) Precast Concrete}

Precast concrete or other concrete secondary elements can be designed on a load factor basis using the ACI 318-71 design code. Where precast concrete is used in a framed structure, attention needs to be drawn to the problems of providing structural separation, and also of meeting the demands for any fire ratings, and smoke stopping required.

\section{(d) Timber Partitions}

Where a fire rating is required with light weight partitions of timber framing, the frame is usually lined with some form of fibrous plaster sheeting which results in them being relatively stiff with a significant resistance to in-plane loadings.

Some tests indicate that such partitions have a stiffness of the crder of $5 \mathrm{kn} / \mathrm{m}$ for deflections of 20 on a height of 2400 . The actual stiffness will depend on the effectiveness of fixings and the number and thickness of layers of lining. At this stage it is considered prudent to allow for a head joint capable of some degree of sliding.

CK5.2 As at March 1977, some local authorities have not adopted NZS 4203 as part of their building By-Laws. Also at present the NZS 1900 series model building By-Laws are being used as design standards for materials by most local bodies for compliance with By-Laws for building permit applications. These existing design standards for the various materials are drafted for a working stress or "alternative design method" as laid down in NZS 4203.

Although not specifically stated in NZS 4203, it can be inferred from Clause 1.3.3 that the seismic forces stipulated for parts of a building as determined from Clause 3.4.9 and Table 9 are in fact ultimate load conditions. Until new design standards for materials based on ultimate load design are designated or available there will be some confusion as to the design standards which should be used for seismic loads derived from NZS 4203.

The use of the alternative method, that is a permissable stresses basis would appear to be the most logical course of action to pursue at this stage, particularly when dealing with local authorities and until the NZS 1900 series is replaced in its entirety. The method which appears most logical in terms of reference information is the use of reduced seismic forces and the load combinations as set out in Clause 1.3.3.3 of NZS 4203 .

\section{CK5.6 Non Participating Structural Elements}

NZS 4203 does not specifically deal with seismic induced loads in structural elements which form part of the structure carrying gravity loads but which do not form part of the primary seismic resisting structure.

Where any element is linked to and is required to follow the deformation of the main structure under seismic induced loads, then that element must be capable of supporting the loads induced by that deformation.

Deformation calculated in accordance with Clause 3.8 could well be exceeded in some structures and in localised areas and this should be taken into account in assessing the deformation and consequent forces induced in those gravity load carrying elements which do not participate in and are not designed as part of the primary seismic resisting structure. 